\title{
त्री \\ As teorias da matéria de Francis Bacon e Robert Boyle: forma, textura e atividade
}

Luciana ZATERKA

\begin{abstract}
is
RESUMO

O presente estudo pretende contribuir para o entendimento da química seiscentista, especialmente para aspectos das teorias da matéria presentes nas obras de Francis Bacon (1561-1626) e Robert Boyle (16271691). Considerados protagonistas da filosofia experimental na revolução científica da modernidade, esses autores podem enriquecer nossa compreensão da gênese teórica e histórica da química moderna. De fato, notaremos como suas respectivas noções de "forma" deixarão gradualmente de ter uma significação metafísica para ganharem um estatuto mais corporificado e material, colaborando, assim, para o desenvolvimento de uma ciência mais operativa e experimental. Nesse momento, veremos a importância do diálogo dessas teorias da matéria com a química paracelsista, pois ambos os autores ingleses servem-se também de uma concepção de matéria ativa.
\end{abstract}

Palavras-Ghave $\bullet$ Bacon. Boyle. Paracelso. Corpuscularismo. Forma. Espírito. Filosofia experimental. Textura. Matéria.

\section{INTRODUÇÃO}

Para os que se interessam pelas questões históricas e epistemológicas da ciência, ter a oportunidade de estudar a chamada "revolução científica do século xvıı" é um privilégio. Privilégio, por que, talvez, o início da modernidade tenha sido um dos mais ricos e transformadores da história, no sentido em que a ciência aristotélica - que predominou durante dezessete séculos - será gradativamente substituída por uma nova visão que abriu o caminho para o desenvolvimento experimental e operativo da nova ciência da natureza e, como consequência, sabemos, para o "desencantamento do mundo". Acreditamos que a química seiscentista pode ilustrar de maneira singular esse complexo momento histórico, especialmente se nos voltarmos para algumas teorias da matéria presentes no período, com seus respectivos conceitos de forma, textura e atividade. Nesse sentido, objetivamos no presente estudo contribuir para o entendimento da química seiscentista, especialmente para aspectos das teorias da matéria presentes nas obras de Francis Bacon (1561-1626) e Robert Boyle (1627-1691). Considerados "ícones" da modernidade, esses autores poderão enriquecer nossa compreensão da 
gênese da química moderna. De fato, notaremos como suas noções de forma deixarão gradualmente de ter uma ênfase metafísica para ganharem um estatuto mais corporificado, material, colaborando, assim, para o desenvolvimento de uma ciência mais operativa e experimental. Nesse sentido, as filosofias de Bacon e de Boyle concentrarse-ão no poder dos experimentos que podem alterar os arranjos íntimos dos corpos e suas relações, portanto, em um conhecimento que tem mando e domínio sobre a natureza. A ciência, de agora em diante, será conduzida pelo homem de ciência, entendido como "ministro e intérprete da natureza", isto é, preocupado com um conhecimento que vincula o saber teórico com o âmbito prático e operacional, este último norteado pela sua utilidade e proveito para o bem-estar da maioria.

\section{BAGON ENTRE A FÍSICA E A METAFísica}

Para compreendermos a importância dessa nova relação introduzida pela modernidade entre o homem e a natureza, vejamos, inicialmente, alguns aspectos da obra daquele que é considerado um dos arautos da ciência moderna: Francis Bacon. Por meio de sua filosofia talvez possamos aproximar-nos do novo quadro de referência metafísicofilosófico do pensamento seiscentista em geral, particularmente, da afirmação de que a ciência deve, antes de mais nada, ser útil e proveitosa para o bem-estar da maioria; concepção esta que decorre dos limites do conhecimento humano sobre os fenômenos da natureza, isto é, da impossibilidade de conhecermos as essências ou as formas substanciais. Restará, portanto, um conhecimento a posteriori, ou seja, dos efeitos para as causas realmente existentes. Em outras palavras, gera-se a confiança - que irá cada vez mais dominar o ideal da modernidade - no caráter político-social da nova filosofia experimental da natureza. De fato, ao criticar aspectos centrais da tradição aristotélica, Bacon propõe um novum organum, isto é, um novo instrumento que favoreça efetivamente a descoberta ou invenção de novos saberes, e não se limita, portanto, ao que ele acredita serem processos tautológicos inúteis, tais como os silogismos. Essa proposta tem como fio condutor o seu importante aforismo inI do Livro I do Novum organum: "ciência e poder do homem coincidem, uma vez que, sendo a causa ignorada, frustrase o efeito. Pois a natureza não se vence, senão quando se lhe obedece. E o que à contemplação apresenta-se como causa é regra na prática". Aqui, o filósofo aponta para a imbricação do âmbito teórico do conhecimento com o âmbito prático, ou seja, que a filosofia natural deve incluir não somente o conhecimento das causas, o que desde Aristóteles ninguém questiona, mas também deve produzir os mesmos efeitos por meio de nossa intervenção. É por isso então que “ciência e poder do homem coincidem”, o conhecimento da causa e a produção dos efeitos devem estar relacionados a um mesmo 
fenômeno: "O homem, ministro e intérprete da natureza, faz e entende tanto quanto constata, pela observação dos fatos ou pelo trabalho da mente, sobre a ordem da natureza; não sabe nem pode mais" (NO, I, I). Nesse sentido, o pensador inglês, ao destruir dicotomias importantes como teoria/prática, scientia/potentia, contemplação/atividade, almeja substituir a concepção predominante de ciência contemplativa por uma nova concepção que se insira na vida prática.

Eu, sem dúvida, aprovo uma divisão desse tipo (...) que sejam estas as duas partes da filosofia natural: a inquisição de causas e a produção de efeitos, o especulativo e o operativo, a ciência natural e a prudência natural. Pois, assim, como nas coisas civis há uma sabedoria do discurso e uma sabedoria da direção, o mesmo ocorre nas naturais (...) há uma interrelação entre causas e efeitos, de modo que esses dois conhecimentos, o especulativo e o operativo, mantém um forte vinculo entre si (ADV, III, p. 351).

O pensador propõe, então, algo inovador: trocar os livros pela natureza, a biblioteca pelo laboratório, acreditando que o homem deva desvencilhar-se da metafísica escolástica e voltar-se para os eventos da natureza.

Ora, como podemos conciliar esse aspecto operativo da proposta baconiana do saber com a sua complexa e difícil teoria das formas? Teoria que, por um lado, deve ser estudada, segundo Bacon, pela própria metafísica, mas que, por outro, encontra-se, sabemos, no cerne de seu projeto científico-filosófico, mobilizando conceitos importantes tais como o de processo e o de esquematismo latentes, estes últimos relacionados com a teoria baconiana da matéria. Se analisarmos o estatuto dessa complexa teoria das formas, discutindo a estreita ligação entre ela e a teoria da matéria de Bacon, veremos que a forma baconiana distancia-se de conotações estritamente metafísicas e insere-se em uma concepção prática e operativa. Para tanto analisaremos especialmente os primeiros aforismos do Livro in do Novum organum (1620) e trechos do Progresso do conhecimento (Advancement of learning) (1605).

Poderíamos indagar por que o arauto da nova ciência teria utilizado um vocabulário tão carregado de sentido pela tradição para um conceito chave de sua obra. Em primeiro lugar, é bom sempre lembrarmos que Bacon é um pensador do século XVII, do início da chamada modernidade e, portanto, o seu pensamento está impregnado de aspectos antigos e modernos, que conformam o rico universo seiscentista. Essa perspectiva será manifesta quando aprofundarmos o estudo da sua teoria da matéria. Lorde Verulâmio, sem dúvida - assim como muitos pensadores do período aponta para aspectos inovadores do conhecimento como, por exemplo, a questão proveitosa e útil da nova ciência por meio de um método experimental aplicado aos fenô- 
menos naturais, mas simultaneamente adere ao sistema geocêntrico do cosmos e é também influenciado pela alquimia paracelsista. Assim, tentemos, antes de mais nada, estudar a filosofia de Bacon respeitando o complexo ambiente do período. Em segundo lugar, com relação especificamente ao conceito de forma, o próprio Bacon afirma que as "formas são simples ficções do espírito humano, a não ser que designemos por formas as próprias leis do ato" (NO, I, LI, grifo nosso). Assim, parece que, por um lado, a forma no seu sentido tradicional, seja platônico ou aristotélico, recebe críticas enfáticas do pensador inglês, mas, por outro lado, ele pretende elaborar um novo conceito no qual a forma abarca "as próprias leis do ato". Em outras palavras, ele mantém o vocabulário da tradição - pois é de uso corrente e familiar - mas pretende dar-lhe outro significado. Analisemos então, inicialmente, esse aspecto crítico apontado por Bacon, para, em seguida, determo-nos na sua concepção, digamos, positiva.

Bacon depara-se com uma questão que sempre inquietou os estudiosos com relação ao conhecimento dos corpos da natureza. Por que os objetos naturais são caracterizados por um aspecto externo determinado? E essa aparência externa, por sua vez, é determinada ou não por uma natureza interna correspondente? O problema para o filósofo natural tem sido, então, o de definir e explicar como esses dois aspectos de um corpo estão relacionados, e como o caráter interno pode dar origem a uma configuração externa. A confiança na imbricação desses dois âmbitos é mostrada pelo uso da mesma palavra "forma" - tanto na tradição grega com o termo eidos, como forma na tradição latina - para significar tanto a "forma" externa de um objeto, como também a sua natureza interna ou essência. Ora, encontramos ao longo da história algumas definições que conceitualizam a forma como a estrutura de alguma coisa distinta de seu âmbito material, isto é, como a natureza essencial de uma coisa separada de sua matéria. Por outro lado, encontramos outras definições que aproximam a forma da materialidade, isto é, para alguns pensadores, a forma - aquilo que, no limite, define a ordem e o padrão dos fenômenos da natureza - atua por meio da matéria, embora não possa ser identificada estritamente com a sua corporificação material exterior (cf. Emerton, 1984, p. 19). Tanto é assim que poderíamos, por exemplo, definir a forma como a configuração física característica dos seres e das coisas, como decorrência da estruturação das suas partes. Observamos, assim, que a forma pode tanto ser definida e explicitada de um ponto de vista mais metafísico, abstrato, ou essencial, ou de uma perspectiva mais material, mais corporificada.

Ao analisarmos o aspecto crítico do termo baconiano "forma", de imediato percebemos que ele se distancia radicalmente da noção platônica, ou seja, com a essência inteligível separada do sensível: forma é, antes de mais nada, a estrutura interna de um corpo, constituída por partículas que conferirão determinadas propriedades, atribuindo-lhe assim sua especificidade. 
É manifesto que Platão, homem dotado de elevado engenho, como situado sobre um penhasco, proclamou em sua teoria das ideias que as formas constituíam o verdadeiro objeto do conhecimento, mas perdeu o fruto genuíno de sua teoria ao considerá-las algo totalmente abstraído da matéria, não algo confinado e determinado por ela, e orientando, portanto, sua visão para a teologia, da qual está contaminada toda sua filosofia natural (ADV, III, p. 355).

Bacon enfatiza aqui a distinção entre a concepção platônica das formas divinizadas, eternas e incorpóreas, formas essas que seriam, em última instância, o fundamento ideal da própria realidade material sensível, e a verdadeira teologia de inspiração cristã, que estuda a palavra de Deus expressa na Bíblia, apoiando seus argumentos também na tradição pagã (grega) e na patrística. Por outro lado, poderíamos pensar que a inseparabilidade entre o corpo e a forma poderia aproximar a noção baconiana da de Aristóteles, na medida em que toda forma é forma de uma matéria. Todavia, a forma baconiana não é um ato exercido sobre uma potência material, pois a forma é também a lei interna e a organização interna de um corpo (cf. Zaterka, 2004, p. 111). Analisemos então o sentido próprio que Bacon fornece ao termo. Para tanto será imprescindível compreender a resignificação que o pensador inglês propõe da teoria das quatro causas de Aristóteles.

Bacon utiliza novamente a terminologia corrente, causa eficiente, causa formal e causa material, porém distancia esses conceitos do sentido clássico aristotélico. Tanto é assim que exclui do âmbito físico o telos, a causa final, aliás, a causa mais importante para o filósofo estagirita. Para Bacon, "a causa final longe está de fazer avançar as ciências, pois na verdade as corrompe” (NO, II, II). E afirma ainda,

Pois o tratamento das causas finais misturadas com as demais nas investigações físicas interceptou a investigação severa e diligente de todas as causas reais e físicas, e deu ocasião aos homens de deterem-se nessas causas meramente agradáveis e especiosas, com grande freio e prejuízo de outros descobrimentos. Isso encontro feito não só por Platão, que sempre lança a âncora nessa margem, mas por Aristóteles, Galeno e outros, que também caem usualmente sobre esses baixios das causas discursivas (ADV, III, p. 358).

Impor a finalidade na realidade física é impedir o avanço do conhecimento. Em outras palavras, operar com o âmbito teleológico na natureza é obstruir o estudo das outras causas envolvidas na realidade dos fenômenos da natureza, quais sejam, as causas eficiente e material para o domínio da física, e a causa formal para o domínio da metafísica. 
Pois, assim como a filosofia natural em geral a dividíamos na investigação de causas e produção de efeitos, assim essa parte que se refere à investigação das causas a subdividimos de acordo com a divisão estabelecida e correta das causas: uma das partes, que é a física, estuda e ocupa-se das causas material e eficiente, e a outra, que é a metafísica, ocupa-se das causas formal e final (ADV, III, p. 354).

Bacon acredita que, para chegarmos ao estudo da física e, portanto, atingirmos o conhecimento das causas material e eficiente, devemos sempre iniciar o percurso pela história natural. Nesse sentido, a história natural, isto é, a investigação exaustiva de todos os dados empíricos, que se possam observar, coletar e classificar, possui um lugar privilegiado no empreendimento do autor do Sylva sylvarum, livro, aliás, que é por excelência uma "coleção de coleções". Em outras palavras, a proposta baconiana de uma reforma total do conhecimento só é possível se, original e fundamentalmente, estabelecer-se uma história experimental da natureza, "pois o conhecimento é como uma pirâmide, onde a história é a base; assim, na filosofia natural, a base é a história natural" (ADV, III, p. 356). Ora, vimos acima que, pelo ideal baconiano de ciência, os conhecimentos especulativo e prático estão unidos; assim, a história natural não é uma simples descrição da natureza, mas uma história ativa em que as operações e técnicas humanas incidirão sobre a natureza, dominando-a e transformando-a em proveito do bem-estar da maioria. O homem, minister et interpres da natureza, deverá ser capaz, a partir da historia experimental da natureza, de coletar fatos suficientes para transformar a natureza e, portanto, criar novas naturezas. E aqui chegamos a um ponto central da proposta baconiana de conhecimento. "Engendrar e introduzir nova natureza ou novas naturezas (naturas) em um corpo dado, tal é a obra e o fito do poder humano" (NO, I, II). E o filósofo continua: "e a obra e o fito da ciência humana é descobrir a forma de uma natureza dada ou a sua verdadeira diferença ou natureza naturante ou fonte de emanação". Nesse sentido, Bacon, aderindo aos ideais alquímicos, acredita que a tarefa e o objetivo do poder humano é induzir em um determinado corpo uma nova natureza (cf. Rossi, 2006, pp. 102-9). Para tanto, temos um longo processo para trilhar. Se o projeto inicia-se com a história natural, a seguir devemos encaminharnos para o estudo da física, pois "a física situa-se em um termo ou distância média entre a história natural e a metafísica. Pois a história natural descreve a variedade das coisas, a física, as causas fixas e constantes" (ADV, III, p. 354). Para o conhecimento da física, Bacon propõe o estudo das causas eficiente e material, bem como o entendimento do processo e do esquematismo latentes presentes nos corpos.

No aforismo ir do Livro iı do Novum organum, o pensador inglês afirma que "a causa eficiente e material (tal como são investigadas e admitidas, isto é, como remotas 
e sem o processo latente no sentido da forma) são perfuntórias e superficiais, em nada beneficiando a ciência verdadeira e ativa". Assim, embora Bacon utilize as causas eficiente e material, salienta que, sem o estudo do processo latente e do esquematismo latente, elas não poderão auxiliar, de fato, na busca da verdadeira ciência, porque

os maiores embaraços e extravagâncias do intelecto provêm da obtusidade, da incompetência e das falácias dos sentidos. E isso ocorre de tal forma que as coisas que afetam os sentidos preponderam sobre as que, mesmo não o afetando de imediato, são mais importantes. Por isso, a observação não ultrapassa os aspectos visíveis das coisas, sendo exígua ou nula a observação das invisíveis. Também escapam aos homens todas as operações dos espíritos latentes nos corpos sensíveis. Permanecem igualmente desconhecidas as mudanças mais sutis de forma das partes mais grossas em espaços mínimos. Até que fatos, como os dois que indicamos, não sejam investigados e esclarecidos, nenhuma grande obra poderá ser empreendida na natureza (...) [e, portanto,] o que deve ser sobretudo considerado é a matéria, os seus esquematismos, os metaesquematismos, o ato puro, e a lei do ato, que é o seu movimento (NO, I, L, LI).

A crítica volta-se contra o "empirismo ingênuo" que se limita ao que é imediatamente visível e também àquelas observações operadas pelos novos instrumentos científicos, tais como a luneta e o telescópio. Dessa maneira, podemos notar que os sentidos têm um duplo registro na filosofia baconiana. O primeiro, bem conhecido, será o fio condutor da parte positiva proposta por Bacon; no segundo, agora negativo, os sentidos são compreendidos como uma das causas de nossos preconceitos, são constituintes, portanto, dos ídolos da tribo, ou seja, aqueles que têm a sua origem na própria natureza humana, pois é natural que os homens julguem as coisas, não como elas são, mas como lhes parecem e, por isso, constantemente erram. O que nos importa nesta discussão é que, para o filósofo seiscentista, por causa desses ídolos, os homens ignoram todo um campo imperceptível, acreditando que o visível abarcaria a totalidade do conhecimento humano (cf. Zaterka, 2004, p. 106). Por operar segundo uma analogia hominis, isto é, conforme o homem e não conforme o universo, eles são levados ao erro (cf. Manzo, 2001). É por isso, então, que não podemos deter-nos simplesmente nas causas material e formal, mas devemos levar em consideração o estudo dos processos e esquematismos latentes, pois "toda ação natural depende das coisas per minima ou, ao menos, tão pequenas para atingir os sentidos, ninguém poderá governar ou transformar a natureza antes de havê-lo devidamente compreendido e considerado" (NO, II, vi). Assim, devemos, antes de mais nada, deter-nos tanto nos corpos em movimento, 
ou no que Bacon chama de processo latente, como nos corpos em repouso, o esquematismo latente. Com relação ao primeiro, Bacon afirma que todo o exame da transformação dos corpos deve “(...) investigar o que se perde e volatiliza, o que permanece ou se acrescenta, o que se dilata e o que se contrai, o que se une e o que se separa, o que continua e o que se divide, o que impede e o que retarda, o que domina e o que sucumbe, e muitas outras coisas" (NO, II, vi). E acrescenta que o filósofo natural não pode limitar-se somente à descrição da reprodução operativa dos corpos, mas deve também analisar o que vem antes e depois, o que é mais veloz e mais lento etc. Ambos os conceitos, "processo" e "esquematismo latentes", são metodologicamente inovadores. É por isso que Bacon adverte aos seus contemporâneos que se preparem para conseguir "adentrar em seus íntimos recessos". Bacon esclarece o que entende pelo esquematismo latente no aforismo viı do Livro iI do Novum organum, quando afirma que por meio do conhecimento desse esquematismo poderemos finalmente transformar os corpos, isto é, dotar um corpo com uma nova natureza. Como? Por meio de uma anatomia dos corpos, mas não a anatomia que decepa ou a anatomia química, isto é, a que utiliza o fogo do destilador, pois estas poderão destruir os arranjos ocultos dos corpos. "Em vista disso, a separação e a solução dos corpos não devem ser feitas pelo fogo, mas pela razão e pela verdadeira indução, com auxílio de experimentos, e por meio da comparação com outros corpos e pela redução a naturezas simples e a suas formas que se juntam e combinam no composto" (NO, II, vII). Em seguida, Bacon fornece um exemplo. Devemos investigar em todo e qualquer corpo o que corresponde ao spiritus e o que corresponde à essência tangível, explicitando manifestamente aspectos fundamentais de sua teoria da matéria, bem como sua dívida com a química paracelsista.

Devemos investigar o quanto de espírito e o quanto de essência tangível há em todo corpo, e se esse espírito é copioso e túrgido ou jejuno e parco, se é tênue ou espesso, se mais próximo do ar ou do fogo, se é ativo ou apático, se é delgado ou robusto, se em progresso ou em regresso (...). O mesmo deve ser feito em relação à essência tangível e seus pelos, fibras e sua múltipla contextura, bem como a colocação dos espíritos na substância e seus poros, condutos, veias e células e os rudimentos ou tentativas do corpo orgânico (NO, II, viı). ${ }^{\mathbf{1}}$

\footnotetext{
1 É interessante notarmos por meio dessa citação que Bacon utiliza claramente um vocabulário biológico para enfatizar a estreita relação entre os espíritos e a matéria tangível na composição dos corpos orgânicos, apontando inclusive a necessidade de examinarmos a penetração dos espíritos nos “poros, veias e células". Ora, sabemos que a historiografia clássica coloca R. Hooke (1635-1703) como o primeiro estudioso a criar e utilizar o conceito de célula. Assim, pretendemos no futuro estudar o conceito baconiano de célula para esclarecer questões importantes relativas à história das ciências da vida.
} 
Bacon, assim, afirma que a matéria é composta por espíritos e matéria tangível. Os primeiros são materiais, mas extremamente sutis e voláteis, possuem apetites, desejos e impulsos; portanto, são considerados os constituintes ativos da matéria. Por outro lado, a matéria tangível é passiva, fria e inerte e, assim, bastante resistente às mudanças. Podemos notar a importância dessa "teoria dos espíritos" por uma obra publicada em 1620, intitulada Historia vitae \& mortis. Aqui os espíritos, de fato, têm um lugar central nas discussões "médicas e biológicas" do filósofo seiscentista, pois conhecendo seus mecanismos de ação, poderíamos, no limite, retardar o envelhecimento e a morte. Podemos notar, então, mais uma vez a estreita imbricação na filosofia de Bacon entre o conhecimento especulativo e o âmbito operativo na nova ciência da natureza.

O objetivo de prolongar a vida resume os objetivos do programa de Bacon como um todo. É certo que ele viveu em uma época ordenada pela Providência para o avanço do conhecimento, acreditava que a filosofia deveria melhorar as condições materiais da raça humana e, em parte, restaurar a felicidade prelapsaria. Ele indicou o prolongamento da vida como o primeiro e mais nobre objetivo da nova filosofia. A realização daquele sonho antigo cumpriria um programa que propusesse uma soteriologia material para este mundo (Rees, 1986, p. xlvi).

Ora, aqui não poderíamos deixar de mencionar as dívidas da proposta baconiana com alguns ideais alquímicos, especialmente paracelsistas.

\section{Paracelso E A GONGePÇÃo de MAtÉria ATIVA}

Para elaborar a sua teoria da matéria, Bacon certamente foi influenciado por elementos do atomismo antigo e da filosofia aristotélica, criticamente considerados, e por diversos pensadores de meados do século xVI e início do século xVII, tais como Bernardino Telésio (1509-1588), Tommaso Campanella (1568-1639) e William Gilbert (1544-1603). Mas, sem dúvida, uma das influências mais marcantes foi a filosofia química de Philippus Aureolus Theophrastus Bombastus von Hohenheim, conhecido como Paracelso (1493-1541). "Paracelso ofereceu o que foi efetivamente a mais importante alternativa para a teoria da matéria aristotélica (...). Certamente não é possível uma compreensão da teoria da matéria de Bacon sem entender um pouco o que a revolução de Paracelso significou" (Gaukroger, 2001, p. 176). De fato, o médico suíço foi o maior expoente dos chamados filósofos químicos do Renascimento. Veremos que, para ele, a chave que permite penetrar nos segredos da natureza seria fornecida pelo estudo da química. Paracelso criticou enfaticamente, em vários momentos de sua obra, a filoso- 
fia antiga e, especialmente, Aristóteles, que considerava um herético. Para ele, como mais tarde para Bacon e para Boyle, o método aristotélico, sua lógica e seus silogismos são simples vocábulos vazios e, portanto, não acrescentam nada de novo ao verdadeiro conhecimento da natureza, pois "um médico não deve apoiar-se somente naquele conhecimento vazio que suas escolas ensinam, mas aprender de mulheres idosas, egípcios, e pessoas assim, pois eles têm maior experiência em tais coisas que todos os acadêmicos" (Paracelso apud Debus, 1965, p. 22). Por um lado, Paracelso critica o conhecimento estéril das escolas, mas, por outro, já propõe algo em seu lugar, a experiência. Embora não possamos confundir a concepção de experiência e experimentação dos modernos com a de Paracelso, é importante notarmos o lugar de destaque que o químico suíço fornece a ela em sua filosofia. Tendo em vista o âmbito iatroquímico, por exemplo, Paracelso e seus seguidores utilizaram sistematicamente a observação e a experimentação e "essa longa tradição resultou não somente no desenvolvimento de testes isolados, mas de procedimentos analíticos reais" (Debus, 2002, p. 110). Sabemos que vários dos chamados filósofos químicos dessa época tinham grande preocupação com as análises de águas minerais. Com o objetivo de determinar as várias substâncias ativas presentes nas águas minerais, empregaram métodos quantitativos, testes de solubilidade, de chama etc. A boa ciência deveria, sobretudo, enfatizar esse aspecto operativo e prático em que a observação e a experimentação possuem um lugar chave.

Em Labyrinthus medicorum errantium, Paracelso afirma que o verdadeiro médico deve voltar-se primeiro para a sapientia.

A maior e mais alta de todas as qualificações que um médico deveria possuir é a sapientia, isto é, a sabedoria “ e sem esta qualificação todo o seu conhecimento vale pouco ou nada (...) O livro da sabedoria é o reconhecimento da verdade, e a verdade é Deus, pois Ele fez todas as coisas vir à existência, e Ele é a fonte eterna de todas as coisas, é também a origem de toda a sabedoria e o livro no qual a verdade pode ser encontrada sem qualquer interpolação ou erro (LDP, p. 205).

E aqui devemos enfatizar um aspecto do pensamento paracelsista que, aliás, será muito caro a Bacon, a saber, as ciências têm como finalidade o auxílio na restauração do domínio humano sobre a natureza, domínio perdido, sabemos, com a queda original. "E Deus os abençoou, e Deus lhes disse: frutificai, e multiplicai-vos, e enchei a Terra, e sujeitai-a; e dominai sobre os peixes do mar, e sobre as aves dos céus, e sobre todo animal que se move sobre a terra" (Bíblia, I, 28). Essa ideia de restauração é central e um dos alicerces do empreendimento paracelsista. 
Paracelso acredita que somente depois de alcançarmos a sapientia poderíamos estudar verdadeiramente o livro da criação divina, a obra de Deus. Nesse sentido, o conhecimento da natureza está diretamente ligado ao conhecimento sagrado.

A natureza, sendo o universo, é una, e sua origem só pode ser uma unidade eterna. É um organismo no qual todas as coisas naturais harmonizam-se e simpatizam-se umas com as outras. É o macrocosmo. Tudo é o produto de um esforço criativo universal; o macrocosmo e o homem (microcosmo) é um. Eles são uma constelação, uma influência, uma respiração, uma harmonia, um tempo, um metal, uma fruta (LDP, p. 62).

O homem seria, nesse contexto, uma pequena réplica do grande universo e, assim, nele estariam representadas todas as partes daquele. A busca pelo conhecimento no domínio natural reflete o tempo todo a busca pelo conhecimento sagrado. Paracelso procurava, acima de tudo, as correlações entre o micro e o macrocosmos para explicar uma interação universal. E o interessante, do nosso ponto de vista, é que essa relação só poderia ser explicitada, no limite, por meio da química, pois somente ela, por ser uma ciência a posteriori e, portanto, experimental, poderia fornecer a "metodologia” adequada. " "Toda arte requer experiência. Vós não podeis tornar-vos um bom pintor, escultor ou sapateiro lendo simplesmente os livros, muito menos um bom médico sem serdes experimentado (LDP, p. 207)". Assim, parece que Paracelso interpreta o sagrado como a realidade no seu todo e o homem dentro dela; a experiência é o caminho ou o procedimento pelo qual os homens têm acesso ao conhecimento dessa realidade. Em outras palavras, o verdadeiro conhecimento deve apoiar-se, por um lado, na sapientia e, por outro, nas observações e experimentações da natureza. Ora, se a ciência deve, antes de mais nada, lidar com a observação e com os experimentos, nenhuma ciência melhor do que a química, ou a alquimia, para ser a chave dessa nova interpretação do mundo. Vejamos, então, como a natureza torna-se, com Paracelso, um grande laboratório químico (cf. Zaterka, 2004, p.117-25).

Sabemos, por exemplo, que Paracelso explica a criação em termos de uma separação química divina.

O princípio (...) de toda a geração foi a separação (...). Se vinagre é misturado com leite morno, então começa uma separação de matérias heterogêneas de muitas maneiras. O truphat dos minerais traz cada metal a sua própria natureza.

2 Esse aspecto químico enfatizado no presente texto associa-se a princípios alquímicos, pois tal divisão não se coloca para a época estudada. 
Assim foi no mistério. Como tintura macerada de prata, assim o grande mistério, penetrando, reduz toda coisa simples a sua própria essência especial. Com habilidade maravilhosa, ele dividiu e separou tudo, de modo que cada substância foi nomeada a sua devida forma (Paracelso apud Debus, 1965, p. 25).

Para o filósofo, todas as coisas provêm de uma prima materia incriada, denominada por ele mysterium magnum, que foi preparada pelo grande artífice. Neste sentido, o mysterium magnum é a substância a partir da qual todos os outros mistérios vem a ser. Paracelso afirma, em Philosophia ad athenienses (cf. LDP, p. 57-81) que a criação ocorreu em vários estágios. O primeiro foi a separação dos quatro elementos. No segundo, o firmamento foi separado do fogo, espíritos e sonhos foram separados do ar, peixes, sais e plantas marinhas foram separadas da água, e madeiras, pedras, animais e plantas terrestres foram separadas da terra. Fica claro então que Paracelso "fala em termos de uma filosofia química universal, porque o próprio Criador era para ele um processo químico" (Debus, 1965, p. 25). Para Paracelso, por conseguinte, tanto os quatro elementos aristotélicos (terra, água, ar e fogo) como os três princípios que ele introduz (enxofre, mercúrio e sal) originam-se do mysterium magnum, o verdadeiro e único elemento.

A força, única ainda, do mysterium magnum, essa força criativa e materializadora, divide-se, ela também, em forças parciais. O grande mistério da separação faz aparecer três forças principais constituidoras do mundo e dos seus elementos: o sulphur, o mercurius e o sal. Mais um grau de separação, de condensação, de coagulação e o elemento único divide-se, enfim, nos quatro elementos clássicos da física aristotélica: a terra e a água, o ar e o fogo. Cada vez mais a unidade primitiva é diversificada, os quatro elementos e as três forças primitivas que os formam encarnam-se em um grande número de seres, dando nascimento aos corpos, aos metais, aos corpos vivos e, enfim, ao homem. Essas forças lutam entre si, e é a sua luta, e o predomínio de uma ou de outra que explicam a diversidade real das criaturas (Koyré, 2001, p. 48).

Lembremos que o sistema aristotélico dos quatro elementos esteve associado sempre segundo pares das seguintes qualidades: quente, frio, seco e úmido. Paracelso utilizou essa teoria, contudo, recusou a associação entre as qualidades, afirmando que cada elemento representa uma única qualidade. Assim, por exemplo, o fogo, que para Aristóteles era quente e seco, é para Paracelso simplesmente quente. Já os três princípios paracelsistas são considerados substâncias espirituais cujas propriedades aproximam-se do enxofre, do mercúrio e do sal, assim como os encontramos na natureza. 
O enxofre é a causa da combustibilidade e da estrutura; o sal é a causa da solidez e das cores dos corpos, e a qualidade vaporosa deve-se ao mercúrio. "O mundo é uma criação de Deus. No início, Ele o fez em um corpo que consiste nos quatro elementos. Ele fundou esse corpo primordial na trindade do mercúrio, enxofre e sal, e estas são as três substâncias nas quais o corpo inteiro consiste (...)" (Paracelso apud Debus, 1965, p. 29). Como salienta Allen Debus,

aqui os princípios estão sendo usados no sentido de entidades que possuem a habilidade de dar forma aos elementos. Mas suas obras [de Paracelso] diferem em muitas passagens. Alguns acreditam que ele afirma que os elementos são compostos dos princípios e outros insistem que os princípios são compostos dos elementos (...) $O$ valor dos três princípios tem que ser visto principalmente no fato de que foram um conceito eficaz. Os aristotélicos falavam e especulavam sobre os quatro elementos, mas os iatroquímicos viam as frações vaporosas, combustíveis e residuosas durante todo o tempo em que eles faziam uma destilação orgânica (Debus, 1965, p. 29, grifo nosso).

Portanto, paralelamente às discussões de âmbito teórico conceitual, encontramos na filosofia paracelsista uma ênfase no registro operacional e prático das ciências.

Em outras palavras, os três princípios paracelsistas determinavam qualidades que tornariam possível a identificação dos constituintes dos corpos por meio de simples operações químicas. ${ }^{4}$ Tanto é assim que na sua discussão sobre as limitações da teoria dos quatro elementos, ele menciona um exemplo para ilustrar a capacidade dos metais de gerarem uma variedade de "formas". O chumbo pode facilmente adquirir características físicas e químicas muito distintas, por meio de simples e controladas manipulações químicas, por exemplo, ele pode apresentar-se como minium (óxido de chumbo), como ceruse (carbonato de chumbo) ou como vidro (sais de chumbo). Como explicar tais mudanças pela teoria dos quatro elementos? Essa é a questão de Paracelso. E conclui que os metais e os sais teriam uma "versatilidade química" necessária para explicar os processos observados e manipulados na natureza, o que seria impossível pela teoria das formas substanciais, na qual uma "forma" deve ser sempre completamente destruída e dar lugar a uma outra "forma" substancial durante o experimento. Assim, os três princípios seriam, no limite, os componentes mais fundamentais de

3 Vale acrescentar que Paracelso afirma no De mineralibus que "existem tantos enxofres, sais e mercúrios quantos são os objetos" (Paracelso apud Debus, 1965, p. 28). Assim, os três princípios em questão diferem qualitativamente nos diferentes materiais.

4 Grosso modo essas operações químicas eram feitas utilizando o calor seja por decomposição (combustão simples) seja por destilação. Sobre a validade das análises feitas pelo fogo nos séculos XVI e XVII (cf. Debus, 1967). 
todos os corpos da natureza. É por isso que se afirma que a tríade possui um lugar central tanto na cosmologia, como na teoria da matéria de Paracelso (cf. Webster, 2008, p. 132-9). De fato, cada um dos três princípios explicaria, como vimos, as propriedades presentes nos corpos. $O$ enxofre traria estrutura e combustibilidade aos corpos, o mercúrio daria elasticidade e fluidez, e o sal, por fim, seria o responsável pela cor, solidez e pela imutabilidade da matéria. Pela relação constituinte entre o macro/ microcosmos, o pensador suíço defendia que a tríade estava presente tanto no universo, como no corpo humano. Se até então predominava, no âmbito da teoria da matéria, a teoria dos quatro elementos, na medicina de tradição galênica, sabemos, havia o predomínio da teoria dos quatro humores, com as suas respectivas quatro qualidades: sangue (quente), fleuma (úmido), bílis amarela (seco) e bílis negra (frio). Lembremos que a doença consistiria, nesse contexto, simplesmente em um desequilíbrio entre esses humores ou qualidades. Ora, a melhoria do doente poderia ser alcançada pela "cura pelos contrários". Paracelso ao propor sua nova concepção de matéria insere a "cura pelos semelhantes", por meio de substâncias até então muito pouco utilizadas, tais como minerais e metais. Assim, os "remédios químicos", como foram chamados, ganham um lugar de destaque nessa nova filosofia química.

Ora, se a analogia com a alquimia e a química permeia de maneira constituinte toda a filosofia de Paracelso, o filósofo natural, para ele, terá necessariamente que conhecer essas ciências, primeiro, e acima de tudo, para glorificar Deus e, segundo, para atingir o conhecimento de suas obras. Vemos que a química torna-se uma ciência privilegiada para a proposta paracelsista de restauração do conhecimento tanto pelo seu papel determinante no desenvolvimento de aspectos práticos experimentais, como pela própria potência transformadora dos princípios paracelsistas. Essa perspectiva será retomada em alguns aspectos pelas filosofias experimentais de Bacon e Boyle. Contudo, podemos apontar ainda uma outra influência da química paracelsista na filosofia de Bacon.

A noção de espírito foi também amplamente adotada pelos filósofos químicos, como um princípio de movimento e vida. Como vimos acima, os espíritos, separados do ar no segundo dia da criação, ganham um lugar central na cosmologia e na filosofia paracelsista. Em um universo neoplatônico, ou seja, hierarquicamente organizado, o espírito foi considerado como uma substância que se originou nas estrelas e, portanto, era superior até mesmo aos quatro elementos. ${ }^{5}$ As formas dos corpos, nessa perspectiva, possuem uma origem celestial e estão contidas nas sementes que recebem o poder formativo do espírito universal. Trata-se de uma substância disseminada no uni-

5 A noção de espírito tornou-se central para a química e a medicina graças à importante obra de Marsilio Ficino De vita e também o influente trabalho de Severinus Idea medicinae philosophicae (cf. Clericuzio, 2000, p. 37). 
verso, que fornece vida e atividade a todos os corpos. Assim,"(...) Paracelso reintroduz a causa formal no reino mineral insistindo em uma força formativa ou agente para dirigir e moldar a matéria. Esse agente formativo recebeu vários nomes pelos diferentes químicos; no seu aspecto mais formal, foi denominado forma, archaeus, estrela, enquanto na sua corporificação material, foi expresso em termos de sementes químicas, espíritos e princípios" (Emerton, 1984, p. 29). Ora, sustentando a necessidade de espíritos, sementes ou poderes formativos na constituição dos diferentes corpos materiais, essa tradição salientava os aspectos ativos presentes nos corpos. O espírito era visto como um instrumento que capacitava a forma universal a agir na matéria; no limite, ele era o elo de ligação entre a matéria e a forma, e também, entre Deus e a natureza, e entre a alma e o corpo (Emerton, 1984, p. 182). ${ }^{6}$ Para Paracelso, cada corpo possui seu próprio archaeus que controla seu desenvolvimento e sua função. O archaeus é o poder formativo da natureza, que divide os elementos formando-os; assim, é o princípio e a essência da vida.

O archaeus, ou liquor vitae, constitui o homem invisível. O homem invisível está escondido no visível, e é formado na forma do exterior tanto quanto permaneça nesta (exterior). O homem interno é, por assim dizer, a sombra ou a contraparte do corpo material. É etéreo em sua natureza, ainda que seja substância: dirige o crescimento e a formação e dissolução da forma na qual está contido; é a parte mais nobre no homem físico. Como uma imagem do homem é refletida em um espelho, assim a forma do homem físico é refletida no corpo invisível (LDP, p. 221).

E, ainda, no De viribus membrorum, Paracelso afirma que

O archaeus é uma essência que está distribuída igualmente em todas as partes do corpo humano, se este está em uma condição saudável, é o nutrimento invisível a partir do qual o corpo visível tira sua força, e as qualidades de cada uma de suas partes correspondem à natureza das partes físicas que ele contém. O spiritus vitae tem sua origem no spiritus mundi. Sendo uma emanação do último, contém os elementos de todas as influências cósmicas, e é, então, a causa pela qual a ação das estrelas (forças cósmicas) pode ser explicada no corpo do homem invisível (p. 221). 
O conceito de semente foi também utilizado pelos paracelsistas em um sentido bastante similar ao citado acima. De fato, das sementes formadas por Deus na criação originavam-se todos os corpos subsequentes. Os seguidores de Paracelso identificavam a semente com o tria prima. Vários filósofos químicos acreditavam que o sal, o enxofre e o mercúrio eram as sementes ativas, enquanto os tradicionais quatro elementos eram as matérias passivas.

Assim, podemos, por ora, sintetizar três aspectos da obra de Paracelso que serão importantes, senão fundamentais, para a teoria baconiana da matéria: (1) a preocupação da restauração do domínio da natureza perdido com a queda original por meio de uma concepção de ciência a posteriori e, portanto, operativa; (2) uma concepção de matéria ativa; e (3) a importância dada à química, ou à alquimia, para atingirmos o conhecimento verdadeiro dos fenômenos da natureza. Devemos também observar como Paracelso, ao questionar a teoria dos quatro elementos, com a sua noção de forma substancial - e propor no lugar sua tríade química -, opera com uma noção de forma menos abstrata e mais material, embora ainda com um caráter formativo e seminal. É essa noção que será também retomada por Bacon e Boyle. Como vimos acima, ao discutir o esquematismo latente presente nos corpos, Bacon utiliza manifestamente a noção de espírito. Voltemos então ao estudo da teoria baconiana da matéria, especialmente a sua concepção de forma, tendo agora em vista o diálogo com alguns aspectos paracelsistas da matéria, em especial, a "materialidade" da forma, entretanto, mantendo seu caráter seminal, bem como a ênfase no aspecto operativo das ciências.

\section{BAGON E O PROBLEMA DA FORMA}

Discutimos até aqui como Bacon propõe uma nova conceituação das quatro causas aristotélicas. Inicialmente, rompe com a causa final no domínio da natureza, em seguida discute a razão pela qual as causas material e eficiente, quando tomadas isoladamente, não dão conta da explicação dos fenômenos naturais e, nesse momento, aponta para a importância da "dissecação indutiva" dos corpos e a necessidade, então, de conhecermos o íntimo dos corpos por meio dos processos e esquematismos latentes. Assim, fica clara a necessidade do homem de ciência "anatomizar" as partículas mínimas da natureza. E Bacon nos adverte que se devem estudar "as partículas mínimas encontradas na natureza, não os átomos que pressupõem o vazio" (NO, II, vIII, grifo nosso). ${ }^{7}$ De fato, como herdeiro de uma concepção química de matéria, ele acredita na

7 Sabemos da complexa problemática que envolve o atomismo e/ou o pneumatismo ao longo da filosofia de Bacon. O presente estudo leva em consideração somente as obras tardias de Bacon, especialmente o Novum organum. Para um exame minucioso dessa questão, cf. Gemelli, 1996; Manzo, 2008. 
total transformação dos corpos, que alteraria, assim, os limites mais profundos dos mesmos, atingindo, portanto, o sonho alquímico. É por isso que no Novum organum ele enfatiza a importância do estudo dos arranjos, dos processos contínuos e da organização dos corpos, por meio de um exame cuidadoso feito, sobretudo, pela razão e pela verdadeira indução - partindo evidentemente de observações e experimentos rigorosos. É interessante como essa preocupação será manifestamente retomada, como veremos, pelo químico Robert Boyle. De fato, mais do que se preocupar com os constituintes últimos da matéria, Bacon e Boyle parecem estar preocupados com os agregados corpusculares, pois são estes, no limite, os agentes causadores das várias sensações, percepções e qualidades dos corpos. Dessa perspectiva, como ambos os pensadores operam com uma concepção de ciência a posteriori, enfatizam os resultados, as operações, os efeitos produzidos pelos corpos, mesmo porque talvez o conhecimento de essências, formas ou universais seja impossível de ser atingido. E aqui devemos esclarecer nossa posição.

Bacon afirma que o estudo das causas material e eficiente, bem como o estudo dos processos e esquematismos latentes, talvez não sejam suficientes para chegarmos ao verdadeiro conhecimento da natureza. Por quê? "Pois essas investigações (...) dizem respeito ao curso comum e ordinário da natureza, não às leis fundamentais e eternas" (NO, II, IX). No Progresso do conhecimento, o pensador nos fornece um exemplo: "O fogo é causa de endurecimento em relação à argila, causa de liquefação no caso da cera, mas não é causa constante de endurecimento nem de liquefação" (ADV, III, p. 354 ). O fogo aqui é tanto a causa eficiente do derretimento da cera, como a causa eficiente do endurecimento da argila; portanto, essas causas são vistas como variáveis e relativas, cuja importância está em atuar como "veículos para as formas", estas sim "eternas e imóveis". Em outras palavras, quem conhece as causas material e eficiente não consegue alterar os limites mais profundos dos corpos, mas

quem conhece as formas abarca a unidade da natureza nas suas mais dissímeis matérias e, em vista disso, pode descobrir e provocar o que até agora não se produziu, nem pelas vicissitudes naturais, nem pela atividade experimental, nem pelo próprio acaso, nem sequer chegou a ser cogitado pela mente humana. Assim é que da descoberta das formas resultam a verdade na investigação e a liberdade na operação (NO, II, III).

Mas o que é, de fato, a forma para Bacon? Para além das diversas concepções que o pensador oferece para esse conceito ao longo de sua obra, podemos afirmar que a forma é a lei e a organização internas de um corpo que explica, no limite, as propriedades fundamentais e as maneiras de operação dessa organização interna segundo regras 
precisas ou, em outras palavras, as naturezas de um determinado fenômeno, que somente poderia ser alcançada pela verdadeira indução. Assim, devemos salientar dois aspectos que nos parecem importantes na presente discussão. Em primeiro lugar, embora o conhecimento da forma seja do domínio da metafísica, ele é imanente no sentido de que "na natureza só existem corpos individuais que produzem atos puros individuais"; não há, portanto, nada além da constituição interna dos corpos ou dos modos de operação, isto é, das leis. A metafísica, nesse sentido, é parte constitutiva da filosofia natural e esta última estuda o que existe na natureza, ou seja, corpos singulares regidos por leis, por regras causais. De fato, no Progresso do conhecimento, Bacon adverte que até agora os homens confundiram a metafísica com a philosophia prima, acreditando que ambas são a mesma coisa,

pois aquela foi posta como progenitor ou antepassado comum de todo conhecimento, e esta a introduzi agora como um ramo ou descendente da ciência natural. Depreende-se, desse modo, que atribuí à filosofia suprema os princípios e axiomas comuns que são gerais e indiferentes para as diversas ciências. Também lhe atribui a indagação tocante à operação dos caracteres relativos e adventícios das essências (...). Depreende-se igualmente que a teologia natural, a qual até agora vinha sendo tratada como metafísica, eu a encerrei em seus limites próprios. Coloca-se agora a questão do que resta para a metafísica (...). A física deve estudar aquilo que está inserido na matéria e, portanto, é transitório e a metafísica aquilo que é abstrato e fixo (...). A metafísica deve tratar do que supõe além disso na natureza uma razão, um entendimento e um plano (ADV, ıII, p. 353).

E conclui, retomando a divisão do estudo das causas, que a física deve ocupar-se do estudo das causas material e eficiente e a metafísica deve tratar do conhecimento das causas formal e final. Assim, podemos observar que, embora a forma esteja no âmbito da metafísica, ela é entendida como constituinte da nova ciência da natureza. ${ }^{8}$ 
Em segundo lugar, podemos começar a compreender esse importante conceito baconiano no aforismo iv do Livro iı do Novum organum, pois aqui nosso pensador mostra que a forma de um determinado fenômeno é sua causa necessária e suficiente.

Pois a forma de uma natureza dada é tal que, uma vez estabelecida, infalivelmente se segue a natureza. Está presente sempre que essa natureza também o esteja, universalmente a afirma e é constantemente inerente a ela. E essa mesma forma é de tal ordem que, se se afasta, a natureza infalivelmente se desvanece, que, sempre que está ausente, está ausente a natureza, quando totalmente a nega, por só nela estar presente (NO, II, IV).

Ora, a natureza dos corpos, que poderá ser modificada pelo conhecimento das respectivas formas e operada pelo irrestrito poder do homem de intervir nos processos naturais, depende da introdução de naturezas determinadas nos corpos. Essas naturezas são, evidentemente, corpóreas, imanentes, materiais. Além disso, essas naturezas simples são em número limitado, caso contrário, seria impossível tal conhecimento. É por isso também que Bacon se distancia das "formas substanciais" aristotélicas, que aparecem sempre multiplicadas e conduzem a lugar nenhum em um processo tautológico vazio. Portanto, não se deve buscar - e nem seria útil - as formas dos sons ou vozes que compõem as palavras, que, por composição e transposição de letras, são infinitas, mas "pode-se facilmente inquirir as formas daqueles sons ou vozes que fazem as letras simples", as quais, então, conduzem às formas de todas as palavras (ADV, III, p. 355). Temos aqui uma clara analogia entre as naturezas simples que devem ser procuradas e as letras do alfabeto. De fato, em uma obra de 1622, intituladaAbecedarium, o filósofo apresenta uma lista dessas naturezas, caracterizando-as em vinte e quatro pares, tais como raro e denso, pesado e leve, volátil e fixo, estável e fluido etc. O conhecimento dessas naturezas simples e suas transformações em corpos específicos con-

zas nos corpos. Ora, essas naturezas são evidentemente corpóreas e materiais. Em segundo lugar, embora Bacon distinga a metafisica da física, ele claramente mostra que a primeira é constitutiva da filosofia natural, ou seja, embora a forma esteja de fato no âmbito da metafísica, ela é entendida como constituinte da nova ciência da natureza. Todavia, gostaríamos de esclarecer um último ponto. Embora, como sustentamos, Bacon adote uma perspectiva mais material da forma, parece que o progresso do conhecimento não depende, no limite, do conhecimento último das formas; se alcançarmos algumas condições necessárias para a produção dos efeitos, a humanidade já pode tirar proveito disso. Bacon aqui enfatiza o processo do conhecimento, pois como herdeiro de uma concepção de ciência $a$ posteriori, sua ênfase recai no conhecimento dos efeitos dos corpos para as suas respectivas causas. Enfim, o importante é o vínculo entre o conhecimento de algumas "estruturas básicas" da natureza e nossa habilidade para provocar a natureza a ponto de ela manifestar-se produzindo em nós efeitos importantes dos seus processos e esquematismos latentes. Com isso, o lado operacional, prático e proveitoso do conhecimento está garantido. Essa perspectiva, acreditamos, será radicalizada pelos adeptos da nova filosofia experimental como, por exemplo, Boyle e Locke. 
duzirão finalmente ao ideal alquímico: "quem conhecer as formas e os modos de introduzir-se o amarelo, o peso, a ductilidade, a fixidez, a fluidez, a solução etc., e suas graduações e modos, saberá como proceder para conjurar em um único corpo essas qualidades, para conduzi-las à transformação em ouro" (NO, II, v). A pergunta então que devemos, por fim, formular é se é possível atingir tal empreitada? É possível o homem atingir o conhecimento das formas e, portanto, da "essência" mais íntima dos corpos?

Pensamos que a resposta pode conduzir-nos para uma dupla perspectiva. Inicialmente, Bacon nos alerta que

contudo, só a Deus, criador e introdutor das formas, ou talvez aos anjos e às inteligências celestes, compete a faculdade de apreender as formas imediatamente por via afirmativa, e desde o início da contemplação. Certamente, essa faculdade é superior ao homem, ao qual é concedida somente a via negativa de procedimento, e só depois no fim, depois de um processo completo de exclusões, pode passar às afirmações (NO, II, xv).

Assim, ele aponta para a dificuldade e talvez mesmo a impossibilidade de atingirmos o conhecimento pleno das formas. Mesmo porque, como um dos propositores da filosofia experimental, ele só pode aproximar-se da natureza dos corpos por meio de seus efeitos. Ora, nesse sentido, o objetivo principal de Bacon é alcançado, qual seja, por meio do novo método indutivo alguns conhecimentos obtidos na investigação das formas - e esse ponto é fundamental - poderão ser transformados em poderes humanos. Em outras palavras, o progresso do conhecimento não depende do conhecimento último das formas. Se alcançarmos algumas condições necessárias para a produção dos efeitos, a humanidade já pode tirar proveito disso. Nessa concepção do conhecimento como processo, conhecendo de que maneira são produzidos alguns efeitos, já podemos efetuar ações práticas e o lado operativo da nova filosofia experimental da natureza está garantido. Por conseguinte, deixa de ser necessário alcançar o conhecimento de essências ou de formas substanciais. Aqui é importante a conexão entre o nosso conhecimento de algumas "estruturas básicas" e nossa habilidade em provocar a natureza a ponto dela manifestar-se produzindo em nós efeitos indicadores dos seus processos e esquematismos latentes. E como o conhecimento das causas material e eficiente, bem como o estudo dos processos e esquematismos latentes são veículos para as formas, parece que Bacon relaciona a disposição interna dos corpos com o conhecimento das formas. 
Assim, tendo oferecido uma lista de propriedades fundamentais ou "naturezas", que somos capazes de tabular como resultante de nossa percepção sensível, a noção última de forma aponta para aquele arranjo invisível que pode ser responsável por elas. Se existe uma dada natureza que nós percebemos, então deve haver uma forma dela que os sentidos não podem atingir, mas cuja interpretação é obra do intelecto dirigido pelo verdadeiro método, ou seja, pela indução (Péres Ramos, 1996, p. 105).

Ora, dado que a forma é também concebida como lei, Bacon, por fim, pode estabelecer a relação entre o arranjo invisível dos corpos como o responsável pelas qualidades e ações de um dado corpo. Essa perspectiva, que vincula uma concepção mais material da forma, com os esquematismos e arranjos dos corpos, será retomada pelo autor do Químico cético.

\section{Boyle, TEXTURA E ATIVIDADE}

Analisemos então a posição de Boyle, por meio de dois textos considerados centrais com relação a sua proposta corpuscular da matéria, Ensaio do nitro (Essay on nitre) de 1661 e o Origem das formas e qualidades (The origin of forms and qualities) de 1666 . No texto sobre a reintegração do salitre ou nitro sabemos que o químico inglês tem como um de seus principais objetivos destruir a noção de forma substancial. De fato, ao demonstrar experimentalmente que o nitro (nitrato de potássio), pode ser decomposto pelo fogo em nitro fixo (carbonato de potássio) e espírito de nitro (ácido nítrico) e que depois é possível pela simples reunião desses constituintes recombinar novamente a substância original, Boyle facilmente atinge o seu objetivo. ${ }^{9}$ Afinal, para a teoria aristotélica, a "forma" do nitro deveria ser completamente destruída e dar lugar a uma outra “forma” substancial durante o experimento; se a reintegração é possível, uma determinada substância química pode ser separada em constituintes menores, corpúsculos, e voltar ao que ela era inicialmente pela simples reunião desses corpúsculos.

De fato, as doutrinas das formas e qualidades, e geração e corrupção, e alteração costumam ser tratadas pelos filósofos escolásticos de modo tão obscuro, tão perplexo, e de um modo tão insatisfatório, e seus discursos sobre esses assuntos con-

9 É interessante notar que Boyle julgava irrelevante a presença efetiva do carvão (como fonte de carbono) e do ar (como fonte de hidrogênio) para a ocorrência da reação química (o que o levou a equivocar-se em seu entendimento do que se passava no experimento), cf. Zaterka, 2004, p. 160. 
sistem muito mais de noções e sutilezas lógicas e metafísicas do que de observações e raciocínios físicos, que se torna muito difícil para qualquer leitor de capacidade média entender o que eles querem dizer (OFQ, 5, p. 289).

Nesse sentido, Boyle salienta que tal filosofia não conduz à descoberta de novos conhecimentos, restringindo-se a processos circulares inúteis. Tanto é assim que se perguntarmos aos peripatéticos quais princípios explicam, por exemplo, a fluidez, ou a brancura, eles certamente dirão que algo é fluido porque contém ingredientes fluidos, ou é branco porque contém a qualidade da brancura, enfim, tal filosofia seria incapaz de explicar, de fato, a origem e a natureza das formas e das qualidades e sua conexão com a ideia de substância. Além de criticar duramente os aristotélicos, Boyle também critica os químicos. Pois, como vimos, os paracelsistas reduzem todas as substâncias aos três princípios originários. Ora, Boyle afirma que, por meio de seus inúmeros experimentos, pôde notar que nem todos os corpos se reduzem somente a esses três elementos que seriam originários. É nesse sentido que podemos ler, no Químico cético, sua própria concepção de elemento, ou melhor, sua dúvida com relação à existência mesma de tais elementos. Mas se Boyle, como muitos de seus contemporâneos, é um critico da teoria das formas substanciais, isso não significa que ele negue a noção de forma.

Tanto no Ensaio do nitro como na Origem das formas e qualidades, ele propõe afastar as "noções metafisicas e as sutilezas lógicas" no estudo da natureza e pretende claramente, na esteira baconiana, "construir uma história experimental delas". Utilizando, assim, um arsenal de exemplos químicos, tais como, o vidro, o mercúrio, o sal, bem como o estudo de qualidades como o frio e o calor, Boyle afirma que a forma de um determinado corpo não pode ser compreendida como "uma substância real distinta da matéria, mas apenas a própria matéria de um corpo natural, considerada juntamente com o seu modo peculiar de existência" (OFQ, 5, p. 324). Ou ainda, na importante seção XXXII do Ensaio do nitro,

ao que parece por esses experimentos suplementares mais precisos, o corpo todo do salitre, depois de ter sido separado em partes muito diferentes por destilação, pode ser adequadamente reunido em salitre equivalente ao seu corpo inicial. Esse experimento nos fornecerá um nobre e (tanto quanto até aqui pudemos saber) único exemplo, capaz de tornar provável que aquilo comumente chamado da forma de um concreto, que confere a ele seu ser e sua denominação e de onde todas as suas qualidades supostamente derivam (segundo a filosofia vulgar) por não sei que meios inexplicáveis, pode não passar em alguns corpos de uma modificação da matéria de que consistem, cujas partes, estando de tal maneira dispostas em 
relação umas às outras, constituem um tal determinado tipo de corpo, dotado de tais e tais propriedades. Ao passo que, se as mesmas partes estivessem dispostas de outro modo, constituiriam outros corpos de naturezas muito diferentes daquelas do concreto, cujas partes formavam inicialmente e que podem novamente resultar ou ser produzidas após a sua dissipação e aparente destruição pela reunião das mesmas partículas componentes associadas, de acordo com a sua disposição inicial (EN, I, p. 372).

Em Origem das formas e qualidades, ele esclarece a sua posição, propondo que “falará como um corpuscular", isto é, como um adepto da hipótese corpuscular da matéria que, no seu caso específico, significa acreditar que a matéria, grosso modo, é composta por minima naturalia, ou seja, pelas partículas mais simples que poderemos encontrar na natureza, pelos corpúsculos, formados pela forte adesão das partículas mínimas e, por fim, pelos corpos do mundo manifesto. O interessante, do nosso ponto de vista, é que semelhantemente a Bacon, Boyle irá enfatizar o estudo dos agregados corpusculares. Afinal, são esses agregados corpusculares os responsáveis, segundo ele, pelas diversas qualidades e propriedades que percebemos nos corpos. Para atingir o seu objetivo, nosso químico esclarece inicialmente algumas questões com relação à origem mesma da matéria. Afirma que concorda com os filósofos em geral quanto à existência de uma matéria católica ou universal comum a todos os corpos, que pode ser entendida como uma substância extensa, divisível e impenetrável. Mas como explicar, então, a diversidade dos corpos?

Para discriminar a matéria católica ou universal em uma variedade de corpos naturais é necessário que exista movimento em algumas de suas partes designáveis ou em todas (...) a origem do movimento na matéria provém de Deus (...) o Autor das coisas fez, estabelecendo as leis do movimento entre os corpos, e por orientar os primeiros movimentos das pequenas partes da matéria, leva-as a associarse da maneira necessária para compor o mundo (OFQ, 5, p. 3०6).

Nesse sentido, Boyle acredita que o movimento local é a principal causa secundária e o "grande agente" de tudo o que acontece na natureza. E conclui que esses dois princípios católicos da natureza, matéria e movimento, "estando assim estabelecidos, seguir-se-á tanto que a natureza deve ser verdadeiramente dividida em partes (...), que cada um dos fragmentos primitivos ou outras distintas e completas massas de natureza devem ter dois atributos, sua própria magnitude, ou melhor, tamanho, e sua própria figura ou forma" (p. 3o6). Em outras palavras, tanto os mais diminutos fragmentos, como as maiores massas de matéria são igualmente dotados cada um deles por 
um volume e forma determinados. É por isso que, para Boyle, todos os fenômenos observados na natureza são, no limite, produzidos mecanicamente "quer dizer, por aqueles agentes corpóreos que não parecem operar de outro modo senão em virtude do movimento, tamanho, figura e disposição de suas próprias partes" (p.3o6); ou seja, de agora em diante, poderemos explicar os fenômenos presentes no curso ordinário da natureza pelo movimento, figura e arranjo ou disposição de seus constituintes íntimos.

Vimos como os esquematismos e processos latentes têm um lugar central na teoria baconiana da matéria. Boyle, seguindo essa trilha, propõe uma explicação para os efeitos observados nos corpos, por meio de tais "estruturas", ou na sua linguagem, por meio da textura: "a forma baconiana não teve uma descendência direta (...). Talvez seja a 'textura' boyleana que forneça o paralelo mais próximo para a nossa concepção" (Péres-Ramos, 1996, p. 116). De fato, no Novum organum, Bacon parece não se preocupar tanto em discutir as especificidades das partículas mínimas que constituem a matéria, mas preocupa-se com o arranjo dessas partículas, pois, como vimos, essas serão o principal veículo para atingirmos o conhecimento das formas e operarmos sobre a natureza. É nesse mesmo sentido que Boyle enfatiza a distinção entre as partículas mínimas e seus agregados, pois é a partir de tal divisão que surge essa propriedade fundamental para compreendermos a natureza das formas e qualidades dos corpos; "quando muitos corpúsculos reúnem-se como para constituir qualquer corpo distinto (...), então a partir de seus outros acidentes (ou modos) (...) emerge uma certa disposição ou arranjo das partes no todo, que podemos chamar a sua textura" (OFQ, 5 , p. 316). Assim, a textura é o arranjo ou a estruturação dos agregados particulares, sendo estes últimos, os responsáveis pelas naturezas e propriedades presentes na matéria. "Boyle não pretende reduzir a causa formal à material, mas expressar o reconhecimento de que a forma não pode existir ou agir para além da matéria em que ela está imersa. Ele sustentou que a forma foi incorporada na regularidade da ordem divina e a ordem das partículas figuradas e sua textura que implementou o padrão inerente com a qual elas foram dotadas" (Emerton, 1984, p. 144). Boyle explica frequentemente os resultados das reações e operações laboratoriais pela textura dos corpúsculos, o que nos conduz necessariamente para os seus arranjos, esquemas e, portanto, no limite, para as suas figuras e formas. Essa perspectiva pode ser analisada pela crítica que ele faz aos conceitos de geração, corrupção e alteração dos corpos. Inicialmente, ele retoma o que entende por forma,

a convenção de acidentes essenciais tomadas conjuntamente com a diferença específica, que constitui o corpo e o discrimina de todos os outros tipos de corpos, é chamada, uma vez que se considera como uma coisa coletiva pelo nome de sua forma (como a beleza, que é constituída apenas pela simetria das partes e a ade- 
quação de suas cores) (...), um estado peculiar da matéria ou, se assim posso chamá-la, uma modificação essencial, ou (...), em uma palavra, sua marca (stamp) (OFQ, 5, p. 334).

Em seguida, ele fará sua critica. Ora, um corpo é capaz de muitas outras qualidades para além daquelas cuja convenção é necessária para constituir a sua forma; assim, a aquisição ou perda de uma dessas qualidades é denominada alteração, quando, por exemplo, o óleo fica gelado, ou muda de cor ou torna-se rançoso. Mas, continua Boyle, se todas ou algumas das qualidades, que são consideradas essenciais a esse corpo, acabam por perder-se ou destruir-se, essa mudança é chamada corrupção, por exemplo, quando o óleo sendo fervido pega fogo, pois, nesse caso, não é dito que o óleo foi alterado, mas corrompido ou destruído, e o fogo emergente gerado. Quando um determinado corpo, por outro lado, corrompe-se lentamente e com isso adquire qualidades "ofensivas" aos sentidos humanos, por exemplo, quando a carne apodrece, chamamos tal corrupção de putrefação. Mas “nem aqui nem em qualquer outro tipo de corrupção existe qualquer coisa substancial destruída, mas apenas aquela especial conexão das partes ou maneiras da sua coexistência, razão por que a matéria (enquanto estava no seu estado inicial) era chamada uma pedra, um metal" (OFQ, 5, p. 335). Notemos então como Boyle aprofunda a noção baconiana de forma, acreditando em uma concepção fortemente material da mesma, a qual é central para fundamentar o seu empreendimento filosófico experimental e, portanto, ativo e operacional. A pergunta então que gostaríamos de formular, por fim, é como Boyle consegue juntar a essa noção de forma material, ao seu corpuscularismo químico mecanicista, uma concepção ativa de matéria que, sabemos, ele herdou das filosofias de Paracelso e Bacon.

\section{Considerações Finais}

Boyle opera com a noção de corpúsculo ou "concreções primárias”, como ele as chama, para explicar inclusive e fundamentalmente tanto a reprodução de substâncias animadas, como até alguns minerais. Assim, esses corpúsculos seriam, no limite, princípios seminais, partículas ativas, dotadas, então, de poderes formativos. Essas concreções primitivas são importantes, pois além de serem extremamente resistentes a modificações, e então persistirem nas reações químicas e restituírem-se em suas formas originais, possuem as exatas texturas para serem capazes de gerar a reprodução de um diverso número de formas, necessárias para dar conta da variedade dos corpos que observamos na natureza (cf. Anstey, 2000, p. 48). Mas, como explicar pelo corpuscularismo mecanicista a presença dessas exatas texturas nos corpos? Aqui, acredita- 
mos ser necessário voltarmo-nos para os fundamentos metafisico-teológicos da filosofia boyleana. Vimos que tanto Paracelso, como Bacon, propõem uma concepção de ciência que seja capaz, antes de mais nada, de recuperar o estado perdido com a queda originária. Nesse sentido, os valores teológicos têm um lugar fundamental. Boyle é um cristão virtuoso que está imerso na tradição teológica ockhamista e filosófica baconiana. Isso significa que ele opera com a contingência no âmbito da filosofia natural. Essa postura traz consequências importantes para a sua filosofia natural, pois o mundo não possui leis necessárias, só regularidades, e não podemos aplicar o método a priori aos fenômenos da natureza e, assim, devemos operar com uma concepção de conhecimento hipotético e experimental, isto é, dos efeitos observados pelos sentidos no mundo para as causas realmente existentes. Essa imbricação é tão importante que nas Origens das formas e qualidades, depois de criticar Descartes, ele afirma:

\begin{abstract}
e, portanto, penso que o sábio autor da natureza não apenas colocou a matéria em movimento, mas quando ele resolveu fazer o mundo, de tal modo regulou e guiou os movimentos das pequenas partes da matéria universal a ponto de reduzir os maiores sistemas de matéria na ordem em que elas deveriam continuar, e, mais particularmente, dispôs algumas porções daquela matéria em rudimentos ou princípios seminais, alojados em receptáculos convenientes (como se fossem úteros) e outros nos corpos das plantas e animais. Uma das principais partes dessa disposição consistia, segundo penso, no seguinte: alguns dos seus órgãos eram estruturados de tal modo que, supondo o edifício dos maiores corpos do universo e as leis que ele estabeleceu na natureza, algumas partes líquidas e espirituosas dessas criaturas vivas devem ser adequadas a transformarem-se em sementes prolíficas por meio das quais elas podem ter um poder, por gerarem seu semelhante, de propagar suas espécies (OFQ, 5, p. 354).
\end{abstract}

Dessa perspectiva, parece que Boyle consegue, então, aderir a um corpuscularismo mecânico, operando, porém, com uma concepção ativa de matéria. Aqui, como vimos, seus pressupostos voluntaristas acerca da criação ganham um lugar de destaque. É nesse sentido que devemos compreender a sua filosofia experimental. E não poderia ser diferente. Mais do que enfatizar o conhecimento da essência ou da substância em geral, essa tradição opera com os efeitos e poderes dos corpos que podem trazer benefícios manifestos para a sociedade. Aqui o caráter público, proveitoso e útil do conhecimento ganha um estatuto ímpar. Boyle trabalha o tempo todo com a hipótese corpuscular da matéria, pois ele não pode, por causa de seu pressuposto voluntarista acerca da criação, falar em leis, ou operar com princípios de uma filosofia dogmática: 
Primeiro, como já declarei em outro lugar, não era meu principal desígnio estabelecer teorias e princípios, mas projetar experimentos e enriquecer a história da natureza com observações feitas e apresentadas de maneira fidedigna, para que, por meio dessas contribuições e outras semelhantes feitas por outros, os homens possam com o tempo ser providos de um estoque suficiente de experimentos sobre os quais fundar hipóteses (Defense, i, p. 121).

Nesse sentido, ele elabora e desenvolve uma concepção de filosofia a posteriori, experimental e operativa, em que o processo científico é mais importante do que a possibilidade de atingirmos as verdades absolutas; estamos no âmbito de "existências" e não de "essências".

É interessante pensarmos que, na mesma época, tínhamos, por exemplo, com as filosofias de Descartes ou Espinosa, uma clara convicção na possibilidade de definirmos a priori a noção de substância com todos os seus acidentes e modos. Contudo, na Inglaterra, pensadores como Bacon e Boyle apontam para os limites desse conhecimento, e aos poucos vão "materializando" a noção de forma, retirando, digamos, seu caráter metafisico, e simultaneamente fornecendo-lhe um estatuto mais corporificado e material, colaborando assim para o desenvolvimento de uma ciência mais operativa e experimental. Pensamos que não é fortuito o fato de Locke ser manifestamente um herdeiro dessa tradição, fazendo inclusive elogios ao método baconiano e à hipótese corpuscular da matéria de seu amigo Boyle e, talvez mesmo por isso, definir, no seu Ensaio, a substância "como um não sei que incognoscível" (Locke, 1979, II, 13, 19). Sem dúvida, a integração da noção de forma com uma determinada concepção de matéria possibilitou a "reintegração da forma em termos corpusculares" (cf. Emerton, 1984, p. 73). Dessa maneira, Boyle consegue operar com as qualidades da matéria, como efeitos da forma, e enfatizar os aspectos ligados à ação, produção e operação dos corpos, tão caros ao projeto baconiano de ciência. Nesse sentido, referindo-se à medicina, ele consegue sintetizar os benefícios e proveitos da filosofia experimental. "Pela decomposição dos corpos, libertando suas partes mais ativas, (...) alterando a textura inicial das produções da natureza ou presenteando-nos com novos concretos de novas texturas (...) deve necessariamente surgir um depósito de medicamentos novos e ativos que com grande probabilidade serão dotados com tais virtudes que não encontramos nos medicamentos comuns" (Usefulness, I, p. 149).@

Luciana ZATERKA

Professora de Filosofia Moderna, Universidade Federal do ABC, São Paulo, Brasil. luciana.zaterka@ufabc.edu.br 


\begin{abstract}
This article aims to contribute to the understanding of seventeenth-century chemistry, especially of aspects of the theories of matter presented in the works of Francis Bacon (1561-1626) and Robert Boyle (1627-1691). These authors, considered proponents of the experimental philosophy of the modern scientific revolution these authors can enrich our understanding of the theoretical and historical origins of modern chemistry. We will discuss how their notions of form gradually cease to have a metaphysical meaning and gain a more embodied and material status, thus contributing to the development of a more operational and experimental science. Since both of these English authors make use of a concept of active matter, we will see here the importance of the dialogue of their theories of matter with Paracelsist chemistry.
\end{abstract}

KeYwords $\bullet$ Bacon. Boyle. Paracelsus. Corpuscularism. Form. Spirit. Experimental philosophy. Texture. Matter.

\title{
REFERÊNGIAS BIBLIOGRÁFIGAS
}

Anstey, P. The philosophy of Robert Boyle. London/New York: Routledge, 2000.

Bacon, F. Novum organum ou verdadeiras indicações acerca da interpretação da natureza; Nova Atlântida. Tradução e notas J. A. R. de Andrade. São Paulo: Abril Cultural, 1979. (Os Pensadores). (NO).

Bacon, F. Advancement of learning. In: Spedding, J.; Leslie, R. \& Heath, D. D. (Ed.). The works of Francis Bacon. London: Longman/Stuttgart/Bad-Cannstatt/Frommann/ Holzboog, 1963 [1857-1874). v. 3, p. $25^{3-491 . ~(A D V) . ~}$

Bíblia. Tradução seiscentista de João Ferreira de Almeida: Rio de Janeiro: Royal Bible, 1997.

Birch, T. (Ed.). The works of the honourable Robert Boyle. London: Olms, 1966 [1772]. 6v.

Boyle, R. The origin of forms and qualities. In: Hunter, M. \& DAvis, E. (Ed.). The works of Robert Boyle. London: Pickering \& Chatto, 1999-2000. v.5, p 281-491. (OFQ).

. A physico-chymical essay containing an experiment with some considerations touching the differing parts and redintegration of salt-petre. In: Вівсн, T. (Ed.). The works of the honourable Robert Boyle. London: Hildesheim, G. Olms, 1966 [1772]. V. I, p. 359-76. (EN).

. Some considerations of the usefulnesse of naturall philosophy. In: Вівсн, T. (Ed.). The works of the honourable Robert Boyle. London: Hildesheim, G. Olms, 1966 [1772]. v. II, p. 64-202. (Usefulness).

. A defense of the doctrine touching the spring and weight of the air. In: Birch, T. (Ed.). The works of the honourable Robert Boyle. London: Hildesheim, G. Olms, 1966 [1772].v. 1, p. 118-77. (Defense).

CLeRICUZio, A. Elements, principles and corpuscles - a study of atomism and chemistry in the seventeenth century. Dordrecht/Boston/ London: Kluwer Academic Publishers, 2000.

Debus, A. The english paracelsians, New York: Franklin Watts, 1965.

. Fire analysis and the elements in the sixteenth and the seventeenth centuries. Annals of Science, 23 p. 29-36, 1967 .

. The chemical philosophy. New York: Dover, 2002.

Emerton, N. The scientific reinterpretation ofform. Ithaca/London: Cornell University Press, 1984.

Fattori, M. (Ed.). Francis Bacon-terminologia e fortuna nel xvii secolo. Roma: Edizioni dell'Ateneo, 1984.

Gaukroger, S. Francis Bacon and the transformation of early-modern philosophy. Cambridge: Cambridge University Press, 2001.

Gemelli, B.Aspetti dell'atomismo classico nella filosofia di Francis Bacon e nel seiscento. Florencia: Olschki, 1996. 
Hartmann, F. (Ed). The life and the doctrine of Philippus Theophrastus Bombast of Hohenheim. Montana: Kessinger Publishing Company, s/d. (LDP).

Hunter, M. \& Davis, E. (Ed.). The works of Robert Boyle. London: Pickering \& Chatto, 1999-2000. 14v.

Koyré, A. Paracelso. Lisboa: Fim de Século, 2001.

Locke, J. An essay concerning human understanding. Oxford: Oxford University Press, 1979.

Malherbe, M. L'induction baconienne: de l'échec métaphysique à l'échec logique. In: Fattori, M. (Ed.).

Francis Bacon - terminologia e fortuna nel ХИІ secolo. Roma: Edizioni dell'Ateneo, 1984. p. 179-200.

Manzo, A. S. Experimentación, instrumentos científicos y cuantificación en el método de Francis Bacon.

Manuscrito, 24, 1, p. 49-84, 2001.

Francis Bacon y el atomismo: uma nueva evaluación. Scientiae Studia, 6, 4, p. 461-95, 2008.

Peltonen, M. (Ed.). The Cambridge companion to Bacon. Cambridge: Cambridge University Press, 1996.

Pérez-Ramos, A. Bacon's forms and the maker's knowledge. In: Peltonen, M. (Ed.). The Cambridge companion to Bacon. Cambridge: Cambridge University Press, 1996. p. 99-120.

Rees, G. (Ed.). The Oxford Francis Bacon. Oxford/New York: Oxford University Press, 1996-2007, 15 v.

ReEs, G. Introduction. In: Rees, G. (Ed.). The Oxford Francis Bacon. Oxford/New York: Oxford University Press, 1996-2007.v. xII, p. xvii-lviii.

Rossi, P. Francis Bacon: da magia à ciência. Londrina: Eduel, 2006.

Spedding, J.; Leslie, R. \& Heath, D. D. (Ed.). The works of Francis Bacon. London: Longman/Stuttgart/ Bad-Cannstatt/Frommann/Holzboog, 1963 [1857-1874). 14v.

Webster, C. Paracelsus, medicine, magic and mission at the end of time. New Haven/London: Yale University Press, 2008.

Zaterka, L. A filosofia experimental na Inglaterra do século XVII: Francis Bacon e Robert Boyle, São Paulo: FAPESP/Humanitas, 2004. 